Nicole K Dalmer

Trent University, Peterborough, Ontario, Canada

\title{
MUTABLE MOBILES: NEGOTIATING TENSIONS IN EVERYDAY INFORMATION WORK IN PAID AND UNPAID DEMENTIA CARE (Paper)
}

\begin{abstract}
This paper details a contemporary, Canadian-centric study that focused on the information work that permeates the care work of families who are caring for a community-dwelling older adult who is living with dementia. Guided by Dorothy Smith's institutional ethnography method of inquiry, thirteen family caregivers of community-dwelling older adults living with dementia were interviewed about their everyday information work. To more fully understand the different influences on family caregivers' experiences of their information work, a second set of interviews was conducted with five paid dementia care staff to understand how, when, and why they provide families with information. This paper's findings make visible the array of carerelated information work that happens in and around the home and calls into question the static boundaries that paid care providers place around information.
\end{abstract}

\section{Introduction}

Recent changes in patterns of care provision for older adults, including those with dementia, include a shifting away from institutionalization and hospitalization (Ward-Griffin \& Marshall 2003). These shifts progressively place a larger proportion of care responsibilities on families, friends, and the surrounding community, who are estimated to contribute an economic value of \$25.5 billion in Canada annually (Hollander, Liu, \& Chappell 2009). With a majority of Canadians living with dementia residing at home (CIHI 2018), caring for a community-dwelling older adult living with dementia living largely relies on the willingness and ability of family members to "assume, master, and maintain the caregiving role" (Hepburn, Tornatore, Center, \& Ostwald 2001, 451). Dependence on family caregivers will continue to grow as Alzheimer's disease and related dementias continue to increase in prevalence and cost, coupled with an increasing neoliberal normalization of aging in place as one ages.

With changing patterns of information provision and consumption, family caregivers are increasingly encouraged to actively and independently seek out information as part of their care work. The provision of information is portrayed as a key component in enabling a caregiver to be involved in the health and wellbeing of the older adult in their care. Dementia Friends Canada, a national awareness campaign between the federal government and the Alzheimer Society of Canada launched in 2015, exemplifies the supposed transformative power of information in caregivers' lives: 'the more you know about dementia, the more prepared you'll be to help people with dementia live better". This emphasis on the expectation of autonomous use of information by carers as a means to meet the complex needs of the older adult is contrasted by a significant number of studies "indicating that extensive unmet caregiver information needs persist” (Washington, Meadows, Elliott, \& Koopman 2011, 39). 
This paper explicates how family caregivers' experiences of their information-related care work come to be and is part of a larger institutional ethnography study that sought to explore how family caregivers' information work becomes shaped by the aging in place institutional complex, including texts, structures, and processes (Dalmer 2018).

\section{Method of Inquiry}

Originating in the 1970s with Canadian sociologist and feminist theorist Dorothy E. Smith $(1987 ; 1999 ; 2005 ; 2006)$, institutional ethnography (IE) is a method of inquiry that maps how people's everyday experiences are "put together by relations that extend vastly beyond the everyday" (Smith 2005, 1). IE is predicated on two underlying assumptions: "(a) social 'happenings' consist in the concerted activities of people and (b) in contemporary society, local practices and experiences are tied into extended social relations or chains of action" (DeVault \& McCoy 2006, 19). Therefore, while rooting itself in individuals' knowledge and the actualities of their everyday experiences, this method of inquiry simultaneously acknowledges that people's everyday, local experiences are permeated and coordinated by relations and institutions that are outside of and may be invisible to those living in their local, everyday environments. To describe and explicate the organization and coordination of people's action, an institutional ethnographer will map out what Smith calls "ruling relations", invisible, translocal forms of control and organization that coordinate what people do with what others are doing "elsewhere and elsewhen" (Smith 2005, 225).

I intentionally frame family caregivers' information practices as work to challenge and expand early (Corbin \& Strauss 1985; 1988) and more recent conceptualizations of information work (Büyüktür \& Ackerman 2017; Hogan \& Palmer 2005; Kaziunas, Ackerman, \& Veinot 2013; Souden 2008) by recognizing the additional work of searching on behalf of or because of another rather than for oneself. In borrowing from Smith's (2005) generous understanding of work, my use of information work acknowledges its complexities, recognizing that information work can be simultaneously instrumental and affective and allows for the incorporation of information management, sharing, and avoidance as work. The use of work to describe families' information practices also recognizes and brings visibility to women's disproportionate care work (Harrington Meyer 2000).

This paper details the results of two sets of interviews: one with 13 family caregivers of community-dwelling older adults living with dementia and a second set with five dementia care staff. The first interview set, ranging between 95 to 185 minutes in length, provides rich descriptions of the everyday information work that family caregivers do and the latter, between 45 to 75 minutes in length, provides an understanding of how dementia care staff's work practices and decisions influence and organize family caregivers' experiences of their information work. As I moved between families' experiences and the broader institutional practices outlined in the dementia care staff's experiences, I searched for "evidence that shows how people's work is tied together across time and location to build a bigger account about how people's work is socially organized" (Rankin 2017, 4). To do so, I employed indexing, an institutional ethnography-focused analytic tool. Indexing is a "tool that can be used to crossreference across work processes, people, and settings" (Rankin 2017, 6). I indexed my transcripts to organize my thinking around linking caregivers' work activities. Fitting both IE's 
understanding of work and my focus on making visible caregivers' work, I indexed anything that the caregivers did that required time and effort.

\section{Findings}

Families' experiences of their information work were linked and organized by timescales of past, present, and future. Family caregivers engaged with information to draw on the past, remain in the present, and to both avoid and plan for the future. It is in their working through the past, present, and future that the complex tapestry of families' everyday and every night information work emerged. All three timescales involved complex configurations between the caregiver, the older adult living with dementia, their extended family, other dementia care partners, healthcare providers, dementia care services and programs, and their broader community. Recognizing that "multiple timelines are involved in complex work" (Davies \& McKenzie 2004), caregivers' timescales were not necessarily linear nor were they sequential, often overlapping, blending, and interfering with one another.

Dementia care staff's work coalesced around three main types of interlinked work that influenced both their and the family caregivers' work: that of coordination, that of making do, and that of accountability. The decisions, policies, and administration processes linked to these three types of interlinked work were outside of what families were aware of but had a direct influence on families' everyday (and every night) information-related care experiences.

\section{Conclusions}

Results from the two sets of interviews with family caregivers and dementia care staff reflect an underlying tension between what Barnes and Henwood (2015) have called informing with care and informing to care. In an inform to care approach, information is "understood as separate and outside of care, while nevertheless acting upon it to produce care" whereas in an inform with care approach, "information is understood as inextricably linked to care (with care) but not in any predetermined or uni-directional sense" (Barnes \& Henwood 2015, 147). Based on this tension, I argue that the two sets of interviews ultimately reveal an ongoing negotiation between the very conceptualization and understanding of the role of information in family caregivers' everyday lives.

The structures that determine paid dementia staff's work ultimately prescribe and set boundaries around information, restricting staff to a more static and less flexible conceptualization of information and of information interventions that are helpful across a number of caregivers. This may explain the proliferation of standardized information booklets, educational photocopies, and brochures that staff pass out to family caregivers. In contrast, family caregivers' experiences of information that ebb and flow in time throughout the caregiving trajectory destabilize this static interventionist approach to information. As family caregivers 'travel' to unpredictable places and experiences of time as the manifestations of dementia progress in strange, unpredictable, and non-linear ways, their experiences of information as fluid, as not too rigorously bounded, appear to be more reflective of reality than the more static or ossified experiences of information, which are more closely aligned with paid dementia staff's ways of engaging with information.

In this way, taking up their information work as fluid and contextual provided an understanding of information work that is more reflective of family caregivers' actualities. Interviewed family 
caregivers' experiences of information in their everyday lives suggest that information can be interpreted as what de Laet and Mol (2000) call "mutable mobiles". Moser (2005) summarizes mutable mobiles as "flexible and responsive objects that become modified and adjusted as they are moved into new contexts and configurations - rather than upon fixed, stable and so immutable mobiles" (367-368). Interpreting information as a mutable mobile lends itself to Barnes and Henwood's (2015) inform with care, as a "new ethical approach to information provision ... which is able to recognise and address the complexity, situatedness and relationality of information-care-giving and care receiving to move beyond the currently dominant inform to care' approach" (153).

Understanding information as fluid in the lives of families begins to explain the increasing responsibility families undertake to become and remain informed while caring for a communitydwelling older adult who is living with dementia; as information takes on a more permeable and loose structure or role in the everyday lives of families, its boundaries can diffuse into increasingly numerous areas of caregivers' lives.

\section{Reference List}

Barnes, M., \& Henwood, F. (2015). Inform with care: Ethics and information in care for people with dementia. Ethics and Social Welfare, 9(2), 147-163.

Büyüktür, A. G., \& Ackerman, M. S. (2017). Information work in bone marrow transplant: Reducing misalignment of perspectives. Proceedings of CSCW (Computer-Supported Cooperative Work and Social Computing) 2017, 1740-1752. http://dx.doi.org/10.1145/2998181.2998361

CIHI (Canadian Institute for Health Information). (2018). How dementia impacts Canadians. Retrieved from https://www.cihi.ca/en/dementia-in-canada/how-dementia-impacts-canadians

Corbin, J., \& Strauss, A. (1985). Managing chronic illness at home: Three lines of work. Qualitative Sociology, 8(3), 224-247.

Corbin, J. M., \& Strauss, A. (1988). Unending work and care: Managing chronic illness at home. San Francisco: Jossey-Bass.

Dalmer, N.K. (2018). Informing care: Mapping the social organization of families' information work in an aging in place climate (Doctoral dissertation). The University of Western Ontario, London, Ontario, Canada. Retrieved from https://ir.lib.uwo.ca/etd/5948

Davies, E., \& McKenzie, P. J. (2004). Preparing for opening night: Temporal boundary objects in textually-mediated professional practice. Information Research: An International Electronic Journal, 10(1). Retrieved from http://www.informationr.net/ir/10-1/paper211.html

DeVault, M. L., \& McCoy, L. (2002). Institutional ethnography: Using interviews to investigate ruling relations. In J. F. Gubrium \& J. A. Holstein (Eds.), Handbook of interview research (pp. 751-776). London: Sage.

de Laet, M., \& Mol, A. (2000). The Zimbabwe bush pump: Mechanics of a fluid technology. Social Studies of Science, 30(2), 225-263.

Harrington Meyer, M. (2000). Care work: Gender, class, and the welfare state. New York: Routledge.

Hepburn, K. W., Tornatore, J., Center, B., \& Ostwald, S. W. (2001). Dementia family caregiver training: Affecting beliefs about caregiving and caregiver outcomes. Journal of the American Geriatrics Society, 49(4), 450-457. 
Hogan, T. P., \& Palmer, C. L. (2005). "Information work" and chronic illness: Interpreting results from a nationwide survey of people living with HIV/AIDS. Proceedings of the American Society for Information Science and Technology, 42(1).

Hollander, M. J., Liu, G., \& Chappell, N. L. (2009). Who cares and how much? The imputed economic contribution to the Canadian healthcare system of middle-aged and older unpaid caregivers providing care to the elderly. Healthcare Quarterly, 12(2), 42-49.

Kaziunas, E., Ackerman, M. S., \& Veinot, T. C. (2013). Localizing chronic disease management: Information work and health translations. Proceedings of the American Society for Information Science and Technology, 50(1), 1-10.

Moser, I. (2005). Information and its uses in medical practice: A critical interrogation of IT plans and visions in health care. International Journal of Action Research, 1(3), 339-372.

Rankin, J. (2017). Conducting analysis in institutional ethnography: Analytical work prior to commencing data collection. International Journal of Qualitative Methods, 16(1).

Smith, D. E. (1987). The everyday world as problematic: A feminist sociology. Toronto: University of Toronto Press.

Smith, D. E. (1999). Writing the social: Critique, theory, and investigations. Toronto: University of Toronto Press.

Smith, D. E. (2005). Institutional ethnography: A sociology for people. Lanham, MD: Altamira Press.

Smith, D. E. (2006). Institutional ethnography as practice. New York: Rowman \& Littlefield Publishers, Inc.

Souden, M. (2008). Information work in the chronic illness experience. Proceedings of the American Society for Information Science and Technology, 45(1), 1-6.

Ward-Griffin, C., \& Marshall, V. W. (2003). Reconceptualizing the relationship between "public" and "private" eldercare. Journal of Aging Studies, 17(2), 189-208. 